\title{
A lusofonia no contexto das identidades transnacionais e transcontinentais
}

\section{Lusophony in the context of transnational and transcontinental identities}

Moisés de Lemos Martins

Universidade do Minho, Instituto de Ciências Sociais
Departamento de Ciências da Comunicação, Braga, Portugal

Professor Catedrático do Departamento de Clências da Comunicaçáa da Universidade do de Comunicacão e Sociedade (CECS), que fundou em 2001, e conta com publicações no campo da sociologia da cultura, semiótica social, sociolog da comunicação, comunicação intercultural e estudos lusófonos.

Ehttp://orcid. org/0000-0003-3072-2904
RESUMO: A lusofonia é uma "comunidade imaginada", de caráter transcultural e transnacional. Tratando-se de um projeto com um passado de cinco séculos, assente no denominador comum que a língua portuguesa constitui, a lusofonia é, simultaneamente, um projeto disperso por vários espaços geograficamente distantes nos quais habitam cidadãos de diversas etnias e com diferentes culturas. Para podermos perspetivar o futuro da lusofonia interessa, por isso, não apenas compreender a sua complexa construção no presente, como também os desafios que tem pela frente. Na ideia de lusofonia joga-se uma luta simbólica pela divisão da comunidade internacional em áreas culturais. Vou, pois, neste artigo, considerar a ideia de lusofonia como um combate pela "ordenação simbólica do mundo" (Bourdieu), onde se colocam os problemas de língua hegemónica e de subordinação científica. E sendo tecnológica a condição da época e o ciberespaço um novo contexto de comunicação, coloco a possibilidade de a lusofonia se construir, também, através de web sites, de portais eletrónicos, de redes sociais, de repositórios digitais e de museus virtuais.

Palavras-chave: Lusofonia; Lusotropicalismo; Língua portuguesa; Identidades transnacionais; Globalização; Poder simbólico.

ABSTRACT: Lusophony is a transcultural and transnational "imagined community". Being a project with a past of five centuries, based on the Portuguese language, Lusophony is simultaneously a project dispersed by several geographically distant spaces in which citizens of diverse ethnic groups and with different cultures live. In order to be able to explore the future of Lusophony, it is therefore important not only to understand its complex construction in the present, but also the challenges that lie ahead. In the idea of Lusophony, a symbolic struggle is played by the division of the international community in cultural areas. I will therefore consider the idea of Lusophony as a struggle for the "symbolic order of the world" (Bourdieu), where the problems of hegemonic language and scientific subordination are posed. Being technological the condition of the time, and cyberspace a new context of communication, I place the possibility of Lusophony being built, also, through web sites, electronic portals, social networks, digital repositories and virtual museums.

Keywords: Lusophony; Lusotropicalism; Portuguese Language; Transnational Identities; Globalization; Symbolic Power 


\section{A lusofonia e o logro da excecionalidade colonial}

erá a ideia de lusofonia um modo de dizer, na atualidade, o conceito $\checkmark$ de lusotropicalismo, o de uma colonização diferente, uma colonização doce, justificada por uma pretensa "excecionalidade portuguesa"? Nas representações de um espaço supranacional de língua e cultura lusófonas existe, muitas vezes, um equívoco lusocêntrico ${ }^{1}$. Nelas sempre Portugal se fixou morbidamente, assombrado pela diferença que o carateriza, ou que imagina como tal, no contexto de outros povos, nações e culturas. 0 grande ensaísta português Eduardo Lourenço refere que o sonho de uma comunidade lusófona, "de uma Comunidade de Povos de Língua Portuguesa, bem ou mal sonhado, é por natureza [...] um sonho de raiz, de estrutura, de intenção e de amplitude lusíada" (LOURENÇO, 1999, p. 162-163).

Quero crer, no entanto, que esta avisada advertência de Eduardo Lourenço não diz, de modo nenhum, todo o sonho da lusofonia, e que nem sequer diz todo o sonho que os portugueses possam ter sobre a lusofonia, por muito que o sonho lusófono preencha para os portugueses um espaço de refúgio imaginário, o espaço de uma nostalgia imperial, que os ajude hoje a sentirem-se menos sós e mais visíveis nas sete partidas do mundo, agora que se encontra definitivamente encerrado o ciclo da sua efetiva epopeia imperial (LOURENÇO, 1983).

Ao falar do sonho da lusofonia, penso que não me refiro a pequena coisa, uma vez que o real, todo o real, começa por ser um sonho na cultura e só depois se torna uma concretização cultural. Com efeito, na era do "sistema mundo" (WALLERSTEIN, 1974, 1980, 1989), parece impor-se, cada vez

\footnotetext{
${ }^{1}$ Por "mundo lusófono", entendo os países que falam português, e também as suas diásporas. Quando me refiro à "lusofonia(s)", quero assinalar as culturas dos países de língua oficial portuguesa, e também as refiro a "lusofonia(s)", quero assinalar as culturas dos paises de lingua oficial portuguesa, e tambem as
diásporas destes países. Sobre o equívoco lusocêntrico da lusofonia, e outros equívocos, ver Martins (2006 e 2014).
}

mais, a ideia de que as alianças e as solidariedades humanas se erguem sobretudo pela força da economia, pelos compromissos políticos e pelo cosmopolitismo técnico-científico. Estou, no entanto, convencido de que os mercados são lugares bem mais de concorrência do que de solidariedade. Nesta era de globalização da economia, penso que faz sentido, mais do que nunca, inverter o aforismo de Marx e acentuar a ideia de que as verdadeiras infra-estruturas da sociedade são "cosa mentale", coisa sonhada, e não propriamente estruturas económicas, mercados e tecnologias (DURAND, 1986, 1997).

Figura 1 - O mundo lusófono, dos países que falam oficialmente a língua portuguesa.

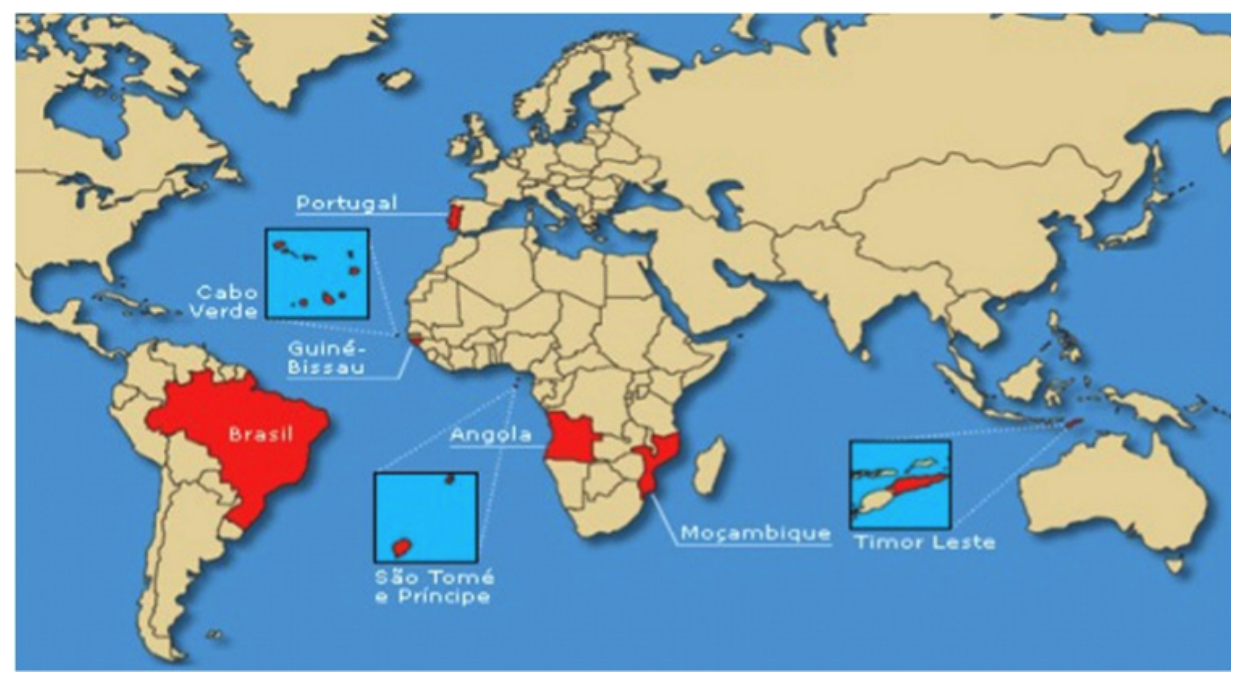

É meu entendimento, com efeito, que não se pode construir uma comunidade viva de coisas mortas. Por exemplo, não foi por um dia a Europa se imaginar de carvão e aço, e, mais recentemente, de Air Bus e TGV, e de muitas mais tecnologias, que ela se está a constituir como comunidade. A 
Europa apenas poderá estabelecer-se na base do seu imaginário plural, ou seja, na multiplicidade das suas culturas.

Por outro lado, o que se joga na ideia de lusofonia é uma luta simbólica pela divisão da comunidade internacional em áreas culturais, dando forma àquilo a que Samuel Huntington (2001) chamou de guerra das culturas. Vou, pois, considerar a ideia de lusofonia como um combate pela "ordenação simbólica do mundo" (BOURDIEU, 1977, 1979, 1980, 1982), onde se colocam os problemas de língua hegemónica e de subordinação científica.

No entanto, este combate político-cultural foi identificado e antecipado, desde os anos trinta do século passado, por Gilberto Freyre, o primeiro pensador "a formular uma teoria geral do fenómeno do encontro de etnias e culturas, no quadro unificador do modelo político da colonização europeia" (MOREIRA, 2000, p. 18). Dando conta de um mundo pela primeira vez globalizado, em que, pelo domínio dos mares, a História ocidental se converteu também pela primeira vez em História mundial (LOURENÇO, 1990, p. 16)², o lusotropicalismo propôs-nos uma cultura regionalista. Não nos propôs sobretudo, nem necessariamente, o "modo português de estar no mundo", como o Estado Novo salazarista o adotou nos anos cinquenta e sessenta em Portugal (CASTELO, 1998) ${ }^{3}$. Propôs-nos, antes, um multiculturalismo com o denominador comum de uma língua "como mátria e como frátria" (FIORIN, 2006, p. 46) ${ }^{4}$.

2 Este ponto de vista tem sido insistentemente desenvolvido pela historiografia contemporânea. Ver, por exemplo, Roger Crowley (2015), Conquerors. How Portugal forged the first global Empire; e Henrique First Global Village: How Portugal Changed the World: e A. G. R. Russell-Wood (1992), The Portuguese Empire, 1415-1808. A World on the Move.

3 Sobre "O global numa visão lusocêntrica", interrogando "o mundo português" da Exposição realizada

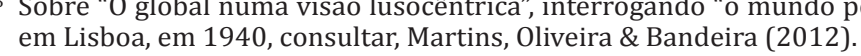

4 "[A lusofonia] Será mátria e será frátria, porque deve ser o espaço de iguais, dos que têm a mesma origem" (FIORIN, 2006, p. 46). Num sentido, todavia, crítico, tanto do lusotropicalismo como da lusofonia, Carlos Alberto Faraco escreveu, em 2016, História Sociopolítica da Língua Portuguesa.
Desde Casa-Grande e Senzala (1933) e Sobrados e Mucambos (1936) que Gilberto Freyre aponta para a redescoberta e a revalorização do "Brasil básico, essencial, popular”, privilegiando memórias, paisagens e alimentos locais, estilos de vida e costumes também locais, enfim, as marcas do quotidiano no coração e na mente: o modo de nascer, comer, habitar, dormir, amar, chorar, rezar, cantar, morrer e ser sepultado.

Ora a lusofonia vai tomar do lusotropicalismo este pendor culturalista e regionalista. Deste modo, diante do imparável processo da globalização cosmopolita, que se ergue diante de nós pela economia e pela tecnologia, deslocalizando-nos, desfazendo fronteiras, diluindo memórias, virtualizando paisagens, aquilo que motiva a lusofonia como coisa que particularmente a carateriza é a globalização multiculturalista, dentro de áreas culturais específicas, uma globalização paradoxalmente regionalista, que se alimenta de um imaginário de territórios, memórias e paisagens vivos e concretos (MARTINS, 2011, 2015, 2017, 2018).

Aquilo que se joga nesta luta simbólica entre globalização cosmopolita e globalização multiculturalista é o poder de definir a realidade, assim como também o poder de impor, internacionalmente, essa definição, quero dizer, essa di/visão (MARTINS, 2011, 2015, 2017, 2018). Neste entendimento, a figura de lusofonia não é uma coisa diferente da realidade social das distintas comunidades nacionais onde se processa esse combate simbólico. E é pelo facto de as representações sociais da realidade não serem estranhas à própria realidade social dos países que as formulam, que, a meu ver, devem ser reavaliadas as formulações que tendem a negar à figura de lusofonia não apenas a eficácia simbólica, como também toda a eficácia política.

A ideia de lusofonia não dispensa, penso eu, a revisitação do sonho lusotropicalista de Gilberto Freyre, que emerge no Brasil desde os anos trinta do século passado, e em Portugal desde os anos cinquenta, por muito que o Estado Novo salazarista o tenha enredado num equívoco colonialista. 
Figura 2 - Este mapa exprime a visão colonial e imperialista do mundo, entre os anos 30 e 60, do século passado, em Portugal. Com colónias que dão para cobrir todo o espaço europeu, "Portugal não é um país pequeno".

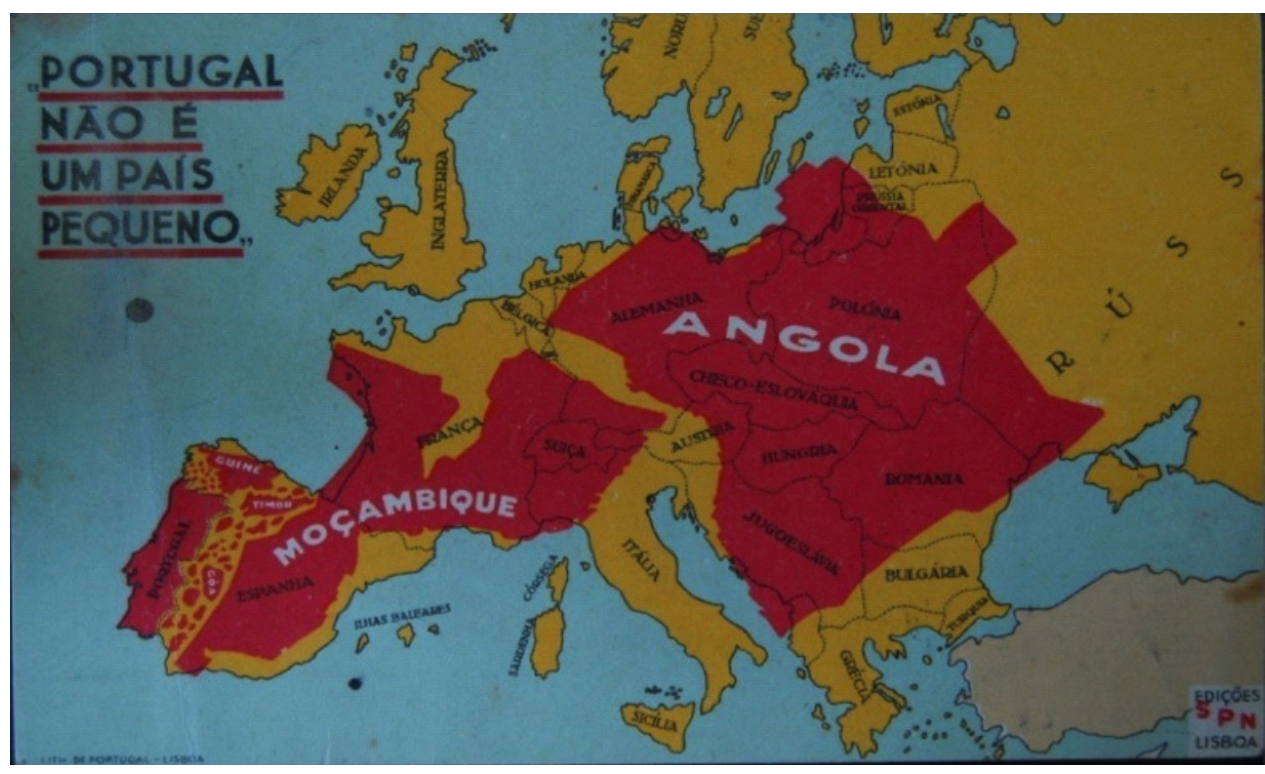

Num e noutro caso, com efeito, prevalece a ideia de que o progresso e a cultura resultam da miscigenação das etnias, e também da miscigenação de memórias, tradições e paisagens. Num e noutro caso, também, impõe-se a ideia de que é possível fazer florescer no seio de uma entidade transnacional, ou supranacional, uma federação cultural com lugar para muitos Estados.

A figura de lusofonia deriva desta raiz lusotropicalista, de que é, em vários aspetos, a meu ver, uma recomposição. Num contexto pós-colonial, mas uma vez liberta da componente colonialista em que o Estado Novo português enredou o lusotropicalismo, a figura da lusofonia convoca, hoje, uma comunidade transnacional, com propósitos político-culturais (CHACON, 2002).
Figura 3 - Este $2^{\circ}$ mapa é a versão internacional da mesma ideia: Portugal e as suas colônias dão para cobrir os Estados Unidos. Portugal não é, pois, um país pequeno; e além disso, as novas combinaçôes de raças e culturas tendem, na essência, a permanecer portuguesas.

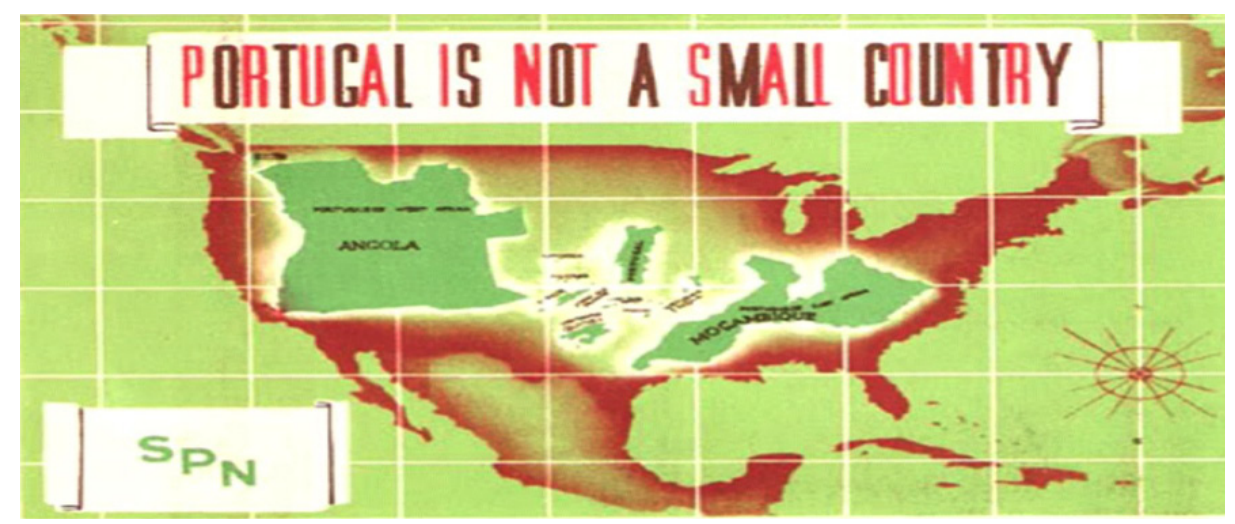

O "Novo Mundo dos Trópicos", afinal O Mundo que o Português Criou, para glosar Gilberto Freyre (1951), não concebe mais na lusofonia novas combinações de raças e de culturas que tendam, na essência, "a conservar-se lusitanas", como o formulou o lusotropicalismo nos anos cinquenta e sessenta. $\mathrm{O}$ "Novo Mundo dos Trópicos" é convocado hoje a exprimir-se em multiculturalismos, com o denominador comum de uma mesma língua. No território imaginário das culturas, é deste modo que eu entrevejo o sonho lusófono ${ }^{5}$.

\section{Cultura e identidade lusófona em contexto tecnológico}

O debate sobre globalização e lusofonia ocorre num contexto póscolonial. Pensar a lusofonia neste contexto não pode, pois, significar o

${ }^{5}$ Este primeiro ponto reescreve e sintetiza o ponto de vista que propus no estudo publicado com o título "Lusofonia e luso-tropicalismo. Equívocos e possibilidades de dois conceitos hiper-identitários" (MARTINS, 2006). 
aplainamento das diferenças entre países muito diversos e heterogéneos, mas ter presente a relação intrincada que os mundos não ocidentais têm com os antigos colonizadores. Antes de mais nada, é preciso ter presente a identidade multicultural e heterogénea que constitui cada comunidade do espaço lusófono. É preciso, ainda, interrogar os média deste espaço, no contexto das estratégias identitárias transnacionais, nacionais e locais.

Por outro lado, as circunstâncias pós-coloniais são as de um mundo mobilizado nas suas práticas por toda a espécie de tecnologias, sobretudo por plataformas móveis de comunicação, informação e lazer (iPad, tablets, smartphones, etc. ), por novas formas de interação social (redes sociotécnicas) e por modelos emergentes de interação (por exemplo, apps e videojogos).

Pensar a lusofonia no quadro alargado de uma reflexão sobre a comunicação e a cidadania é, hoje, antes de mais nada, atender a estas circunstâncias tecnológicas, ou seja, é discutir as suas implicações culturais no espaço lusófono ${ }^{6}$. Mas há que atender igualmente ao modo de produção e circulação de representações sociais que acompanham os processos de discriminação social e xenofobia ou os nacionalismos, ou seja, haverá que discutir a ideia de representação social e a sua articulação com a ideia de estereótipo social. Pensar a lusofonia no quadro alargado de uma reflexão sobre a comunicação e a cidadania passa ainda por interrogar as tensões sociais dentro e fora das comunidades nacionais de referência e os seus níveis de participação cívica, avaliando, por outro lado, o papel dos média no processo social de constituição de estereótipos sociais sobre a etnia e a cor da pele.

\footnotetext{
${ }^{6}$ Tenho insistido na analogia que é possível fazer entre a atual globalização, uma "circum-navegação tecnológica", fundada nas tecnologias da informação, que nos mobilizam para o mercado, e a primeira globalização, concretizada pela expansão europeia nos séculos XV e XVI (MARTINS, 2015, 2015/2016, globalização,
}

Neste entendimento parecem-me merecer particular atenção a análise das sub-culturas juvenis de cariz étnico, urbanas e sub-urbanas, porque se trata de analisar as representações do mundo e os mecanismos de legitimação de novas práticas culturais, reclamadas, umas e outras, pelos mais diversos grupos sociais.

O mundo contemporâneo é essencialmente multicultural. Debater a lusofonia à luz deste entendimento obriga a pensar os fenómenos comunicacionais em termos interculturais. É, no entanto, a realidade de uma língua comum, a língua portuguesa, qualquer que seja a sua forma de existência - língua materna, língua oficial, língua de uso, língua que une hoje cerca de 250 milhões de falantes -, que permite o sonho de um imaginário lusófono, enfim, o sonho de uma comunidade lusófona.

Num contexto pós-colonial, a figura da lusofonia convoca, então, uma comunidade transnacional. 0 seu denominador comum é uma mesma língua, mas é de propósitos político-culturais que ela vive, exprimindo-se através do multiculturalismo e construindo-se pela interculturalidade. Nestas circunstâncias, o debate da lusofonia não pode ser alheio aos processos de "tradução" cultural. E a fundação da Comunidade dos Países de Língua Portuguesa (CPLP), a 17 de Julho de 1996, que compreende hoje oito países lusófonos ${ }^{7}$, assim como os regulares acordos ortográficos para a projeção internacional da língua portuguesa, são expressões do privilégio que é dado à dimensão política e cultural da comunidade lusófona.

Não me parece, todavia, que a figura da lusofonia convoque, hoje, sobretudo, uma comunidade transnacional com propósitos económicos, porque tanto Portugal como o Brasil, que são os principais países lusófonos, têm a esse nível outros quadros de referência que os vinculam, no caso

Na realidade, a CPLP é, hoje, constituída por nove países, dado que a Guiné Equatorial passou a integra esta comunidade, em 2014. Não a consideramos, todavia, no quadro deste estudo, por não ser um país de colonização portuguesa. 
de Portugal a Comunidade Europeia, e no caso do Brasil o Mercosul. Mas acentuo o facto de os propósitos e as estratégias político-culturais prevalecentes se exprimirem, por um lado, através do multiculturalismo, porque existem as realidades múltiplas e heterogéneas, que são a cultura portuguesa, a cultura brasileira, a cultura angolana, a cultura moçambicana, enfim, as culturas dos distintos países de língua oficial portuguesa e das suas diásporas. E acentuo, por outro lado, o facto de os propósitos e as estratégias político-culturais prevalecentes se cumprirem na interculturalidade, uma hibridez que resulta da miscigenação, ou seja, da mistura, do encontro daquilo que é diverso e heterogéneo.

A lusofonia não é, portanto, uma realidade feita. 0 facto de 250 milhões de indivíduos falarem o português é um óptimo ponto de partida para acalentar o sonho de uma comunidade lusófona. Mas a língua, por si só, não nos garante essa comunidade. A comunidade lusófona haverá, pois, que a construir.

\section{A área cultural lusófona e a globalização}

Ao autonomizar-se como variável dominante no mundo, a globalização fracionou as sociedades transcontinentais, cujos projetos todavia a precederam: o Brasil e os Estados Hispânicos convergem no Mercosul; por sua vez, a francofonia, a Comunidade Britânica, a lusofonia e o panarabismo desenvolveram linhas diferenciadas na unidade do continente africano (MOREIRA, 2004, p. 9). Além disso, o Corão apela à identidade de um cordão muçulmano que, de Gibraltar à Indonésia, divide o norte do sul do mundo.

Nestas circunstâncias, é certamente desafiante a tarefa de harmonizar tão diferenciadas e múltiplas filiações, umas baseadas na experiência e na história, outras induzidas pelas leituras do futuro premente. Hoje, todas as áreas culturais falam pela primeira vez com voz própria na cena internacional e veem-se forçadas à convergência pela globalização derivada das revoluções científica, técnica e dos mercados. Neste contexto, cada país vai ter que considerar a ligação a grandes espaços diferenciados e, conjunturalmente, vai ter que considerar também a ligação a espaços com interesses que podem ser contraditórios.

Sendo tecnológica a condição da época e o ciberespaço um novo contexto de comunicação, a lusofonia vai também construir-se através de web sites, de portais eletrónicos, de redes sociais, de repositórios digitais e de museus virtuais ${ }^{8}$. No entanto, a Internet não tem penetrado, de modo homogéneo, as populações dos países dos vários continentes. Pelo facto de ela propulsar a época e nos mobilizar a todos, a Internet penetra de modo mais abrangente as populações dos países mais ricos. Deste modo, as possibilidades abertas pela Internet para a divulgação do conhecimento, assim como para o interconhecimento e a cooperação entre os povos, não favorece por igual todos os povos, nem todas as línguas. No espaço lusófono, por exemplo, a penetração da Internet na população dos países que falam o português como língua oficial é de $32,8 \%$. Mas a penetração no conjunto da população mundial ascende a $49,2 \%$.

E se olharmos, continente a continente, é a seguinte a penetração da Internet na população lusófona, por relação à sua penetração no conjunto da população mundial:

- Em África, a penetração da Internet nos países lusófonos é de 19, 9\%, quando a média de penetração no continente africano é de $26,9 \%$;

${ }^{8}$ A este propósito gostaria de assinalar o Museu Virtual da Lusofonia. Criado no Centro de Estudos da Comunicação e Sociedade (CECS) da Universidade do Minho, o Museu Virtual da Lusofonia é uma plataforma de Sociedac̃a (CECS) da Universiade do Minio, o Museu Virtual da Lusofonia é uma plataforma de cooperação académica em Ciências Sociais e Humanas, vinculada, sobretudo, aos estudos culturais, à comunicação da ciência, ao ensino pós-graduado, e às artes, no espaço dos paíse Museu Virtual da Lusofonia: <http://www. museuvirtualdalusofonia. com/>. 
- Na Europa, a penetração da Internet em Portugal é de 67, 6\%, quando a média de penetração no continente europeu é de 77, 7\%;

- Na Ásia, a penetração da Internet em Timor Leste é de 27,5\%, quando a média de penetração no continente asiático é de 44, 7\%;

- Na América do Sul, a penetração da Internet no Brasil é de 67,5\%, sendo a média de penetração na América do Sul de 66, 7\%.

Com efeito, o Brasil tem uma força de penetração da Internet mais forte que o continente sul-americano. E a mesma coisa acontece com Cabo Verde, relativamente ao continente africano. Cabo Verde tem uma penetração da Internet de $42 \%$, quando a média do continente africano se cifra em $26,9 \%$.

Existe, também, uma grande discrepância de penetração da Internet entre as populações dos diferentes países lusófonos:

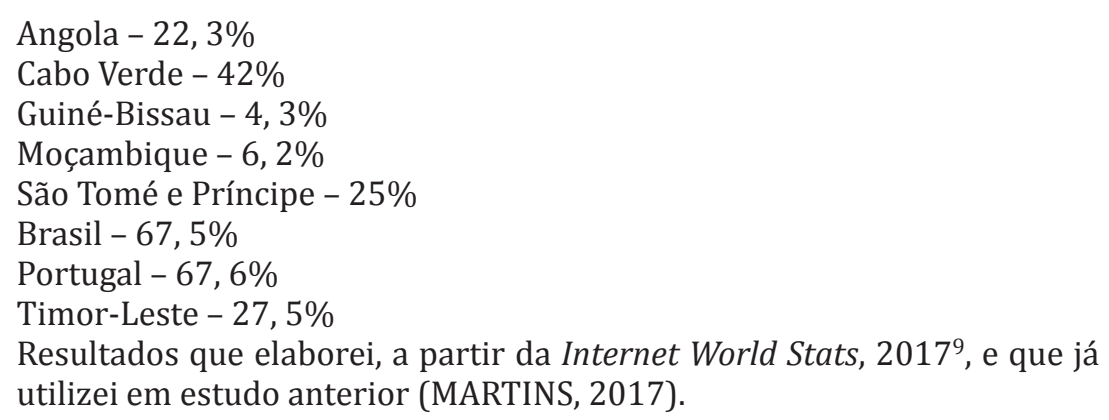

Por outro lado, quando falamos de informação e de comunicação através dos média, seja a imprensa escrita, a rádio e a televisão, seja a Internet, não podemos deixar de ter em atenção que ambas se fazem em línguas, que é sempre necessária uma língua natural para informarmos e comunicarmos. À medida, todavia, que o mundo se torna mais global, que a velocidade dos transportes encolhe as distâncias geográficas, que as redes

${ }_{9}$ Retirado de Internet World Stats, 2017: <http://www. internetworldstats. com/> de telecomunicações se espalham em maior largura de banda, a pressão por uma só língua aumenta.

No entanto, todos aqueles que se acham comprometidos com a língua portuguesa têm que estar nessa luta. Preservar uma língua, expoente máximo de uma cultura, é saber fortificá-la na comunicação diária e global. Neste sentido, é dever dos falantes de uma língua, e portanto tarefa de cidadania, cultivá-la e promovê-la, porque é na língua em que sentimos, pensamos, nos exprimimos e comunicamos, que se joga a identidade de uma povo, de uma cultura, de uma civilização. E mais do que quaisquer outros falantes, são instrumentos ativos dessa fortificação linguística os profissionais da comunicação social, e também os professores de língua e cultura. É um facto que o intercâmbio editorial entre Portugal e o Brasil, e também o intercâmbio destes países com os países africanos de expressão oficial portuguesa e com Timor, continua a ser incipiente. Mas é expectável que a língua funcione aqui como um importante instrumento comercial, cultural e político, num tempo marcado pela globalização, interculturalismo e multiculturalismo. $\mathrm{O}$ que em nada contradiz, todavia, a consideração de realidades nacionais multiculturais em distintas regiões do globo, com a língua portuguesa a ter que se relacionar com outras línguas locais e a ter que entrar em muitos casos em competição com elas.

\section{Referências}

BOURDIEU, Pierre. Ce que parler veut dire. L'économie des échanges linguistiques. Paris: Fayard, 1982.

BOURDIEU, Pierre. L'identité et la représentation. Éléments pour une réflexion critique sur l'idée de région. Actes de le Recherche en Sciences Sociales, 35, 1980.

BOURDIEU, Pierre. La Distinction. Critique sociale du jugement. Paris: Éditions de Minuit, 1979.

BOURDIEU, Pierre. Sur le pouvoir symbolique. Annales, v. 32, n. 3, p. 405-411, 1977. 
BRITO, Regina; MARTINS, Moisés de Lemos. Considerações em torno da relação entre língua e pertença identitária em contexto lusófono. Anuário Internacional de Comunicação Lusófona, 2, São Paulo: LUSOCOM - Federação Lusófona de Ciências da Comunicação, 2004. Disponível em: <http://hdl. handle. net/1822/1679>. Acesso em: 5 jan. 2018.

CABECINHAS, R.; CUNHA, L. (Ed.). Comunicação intercultural: perspectivas, dilemas e desafios. Porto: Campo das Letras, 2008.

CASTELO, Cláudia. O modo português de estar no mundo: o luso-tropicalismo e a ideologia colonial portuguesa (1936-1961). Porto: Afrontamento, 1998.

CHACON, Vamireh. O futuro político da lusofonia. Lisboa; São Paulo: Verbo, 2002.

CROWLEY, Roger. Conquerors. How Portugal forged the first global Empire. London: Faber \& Faber, 2015.

DURAND, Gilbert. O imaginário português e as aspirações do ocidente cavaleiresco. In: Cavalaria espiritual e conquista do mundo. Lisboa: Instituto Nacional de Investigação Científica, 1986

DURAND, Gilbert. Imagens e Reflexos do imaginário português. Lisboa: Hugin, 1997.

FARACO, Carlos Alberto. História sociopolítica da língua portuguesa. São Paulo: Parábola, 2016.

FIORIN, José Luiz. A lusofonia como espaço linguístico. In: BASTOS, N. (Org.). Língua portuguesa: reflexões lusófonas. São Paulo: EDUC, 2006. p. 25-48.

FREYRE, Gilberto. Casa-Grande \& Senzala. São Paulo: Global, 2003 [1933].

FREYRE, Gilberto. Sobrados e mucambos: decadência do patriarcado rural e desenvolvimento urbano. São Paulo: Global, 2006 [1993].

FREYRE, Gilberto. O mundo que o português criou. Lisboa: Edições Livros do Brasil, 1951. GILROY, Paul. The Black Atlantic. Modernity and Double Consciousness. London: Verso, 1998.

HALL, Stuart. The centrality of culture: Notes on the cultural revolutions of our time. In: THOMPSON, K. (Org.). Media and Cultural Regulation. London: Sage, 1996. p. 217-238. HUNTINGTON, Samuel. O choque das civilizações e a mudança na ordem mundial. Lisboa: Gradiva, 2001 [1996].

LEITÃO, Henrique. Os descobrimentos portugueses e a ciência europeia. Lisboa: Alêtheia Editores, 2009.
LOURENÇO, Eduardo. Crise de identidade ou ressaca 'imperial'? Prelo, Lisboa: Imprensa Nacional-Casa da Moeda, n. 1, p. 15-22, out.-dez. 1983.

LOURENÇO, Eduardo. A nau de Ícaro seguido de imagem e miragem na lusofonia. Lisboa: Gradiva, 1999

MACEDO, Lurdes; MARTINS, Moisés de Lemos; MACEDO, Isabel. 'Por mares nunca dantes navegados': contributos para uma cartografia do ciberespaço lusófono. Anuário Internacional de Comunicação Lusófona, “2010 Lusofonia e Sociedade em Rede”, 2010. p. 11-39. Disponível em: <http://hdl. handle. net/1822/36699>. Acesso em: 4 out. 2017.

MARTINS, Moisés de Lemos. Communication studies cartography in the Lusophone world. Media, Culture \& Society, v. 40, n. 3, p. 1-6, 2018. DOI: 10.1177/ 0163443717752812 journals. sagepub. com/home/mcs

MARTINS, Moisés de Lemos. A internacionalização das comunidades lusófonas e iberoamericanas de Ciências Sociais e Humanas - O caso das Ciências da Comunicação. Famalicão: Húmus, 2017. Disponível em: <http://hdl. handle. net/1822/49365>. Acesso em: 5 jan. 2018.

MARTINS, Moisés de Lemos. Ciências da Comunicação e Mundo Lusófono. Anuário Internacional de Comunicação Lusófona. Santiago de Compostela: Lusocom/Agacom, 2015/2016. Vol. XIII, p. 11-18. Disponível em: <http://hdl. handle. net/1822/45164> Acesso em: 8 jan. 2018.

MARTINS, Moisés de Lemos. Lusofonia e interculturalidade. Promessa e travessia. Famalicão: Húmus, 2015. Disponível em: <http://hdl. handle. net/1822/39693>. Acesso em: 5 jan. 2018

MARTINS, Moisés de Lemos. Língua Portuguesa, globalização e lusofonia. In: BASTOS, N. M. (Org. ). Língua portuguesa e lusofonia. São Paulo: EDUC - IP-PUC, 2014. p. 15-33. Disponível em: <http://hdl. handle. net/1822/29178>. Acesso em: 8 jan. 2017.

MARTINS, Moisés de Lemos. Globalization and Lusophone world: implications for citizenship. In: PINTO, M.; SOUSA, H. (Org.). Communication and Citizenship: Rethinking Crisis and Change. Coimbra: Grácio Editor, 2011. p. 75-84. Disponível em: <http://hdl handle. net/1822/25344>. Acesso em: 1oo out. 2017.

MARTINS, Moisés de Lemos. Lusofonia e luso-tropicalismo. Equívocos e possibilidades de dois conceitos hiper-identitários. In: BASTOS, N. (Ed.). Língua portuguesa: reflexões lusófonas. São Paulo: EDUC, 2006. p. 49-62. Disponível em: <http://hdl. handle. net/1822/1075>. Acesso em: 4 out. de 2017. 
MARTINS, M. L.; OLIVEIRA, M.; BANDEIRA, M. O "Mundo Português" da Exposição de 1940 em postais ilustrados: o global numa visão lusocêntrica. Revista de Comunicação e Linguagens, v. 42, p. 265-277, 2012. Disponível em: <http://hdl. handle. net/1822/24149>. Acesso em: 8 jan. 2018.

MARTINS, Moisés de Lemos. A lusofonia como promessa e o seu equívoco lusocêntrico. In: MARTINS, M. L.; SOUSA, H.; CABECINHAS, R. (Ed.). Comunicação e Lusofonia: para uma abordagem crítica da cultura e dos média. Campo das Letras: Universidade do Minho/CECS, 2006. Disponível em: <http://hdl. handle. net/1822/29957>. Acesso em: 8 jan. 2018.

MOREIRA, Adriano. Revisitar Gilberto Freyre. In: MOREIRA, A.; VENÂNCIO, J. C. (Ed.). Luso-tropicalismo: uma teoria social em questão. Lisboa: Veja, 2000.

PAGE, Martin. The First Global Village: How Portugal Changed the World. Lisboa: Casa das Letras, 2002.

RUSSELL-WOOD, A. G. R. The Portuguese Empire, 1415-1808. A World on the Move. Balimore: Johns Hopkins University Press, 1992.

SOUSA, Helena. Os media ao serviço do imaginário: uma reflexão sobre a RTP Internacional e a Lusofonia. Comunicação e Sociedade, n. 2, Braga: NECS, 2000.

WALLERSTEIN, Emmanuel. The Modern World-System. Vol. I: Capitalist Agriculture and the Origins of the European World-Economy in the Sixteenth Century. New York/ London: Academic Press, 1974.

WALLERSTEIN, Emmanuel. The Modern World-System. Vol. II: Mercantilism and the Consolidation of the European World-Economy, 1600-1750. New York: Academic Press, 1980.

WALLERSTEIN, Emmanuel. The Modern World-System. Vol. III: The Second Great Expansion of the Capitalist World-Economy, 1730-1840's. San Diego: Academic Press, 1989.

\section{Sites:}

INTERNET World Stats, 2017: <http://www. internetworldstats. com/>.

MUSEU Virtual da Lusofonia: <http://www. museuvirtualdalusofonia. com/>.

\section{Recebido em 03/08/2017}

Aceito em 20/01/2018. 